\title{
A rare cause of intestinal obstruction in a newborn: Congenital band compression
}

\author{
Emrah Aydin \\ Bahcelievler State Hospital, Istanbul, Turkey
}

\begin{abstract}
Congenital band compression syndrome should be considered in cases diagnosed prenatally or postnatally as intestinal obstruction. Presently described is a report of newborn admitted to hospital with abdominal distension and bilious vomiting. A suspected intestinal obstruction had been diagnosed in prenatal examination. Surgery revealed congenital band compressing ileal segments and preventing transmission of intestinal content. Band was successfully removed and intestinal integrity is intact.
\end{abstract}

Keywords: Congenital band compression; intestinal obstruction; newborn.

\footnotetext{
Cint
} ongenital band compression is one cause of intestinal obstruction. It is a pathology usually encountered during childhood. Preoperative diagnosis is challenging [1]. Bands are considered remnants of fetal vessels and ventral mesenterium that are ordinarily resorbed [1]. The present case is a report of a patient with congenital simple band compression. Due to suspicion of intestinal obstruction observed prenatally, and because of inability to demonstrate intestinal continuum during postnatal period, surgery was performed.

\section{CASE REPORT}

A newborn girl with birth weight of 2440 gr who was born via vaginal route to a healthy, gravida 1 , para 1 mother at 37 weeks' gestation was admitted to clinic with vomiting and abdominal distension. On physical examination, metallic bowel sounds were heard, abdominal distension was observed, and patient had not yet defecated. Bilious discharge was detected emerging from nasogastric tube. Rectal irrigation did not elicit a defecation response. Blood gas and biochemical values were within normal limits. Upright, plain abdominal radiographs revealed small air-fluid levels and passage of gas to distal area (Figure 1). Whole abdominal ultrasound did not reveal any intra-abdominal mass lesion. $\mathrm{Ra}$ diographs obtained after rectal administration of contrast material showed unused large bowel (Figure 2). Radiograms obtained following oral intake of contrast material showed no passage of contrast material beyond ileal level, prompting decision to perform surgery. Surgical exploration disclosed con- 


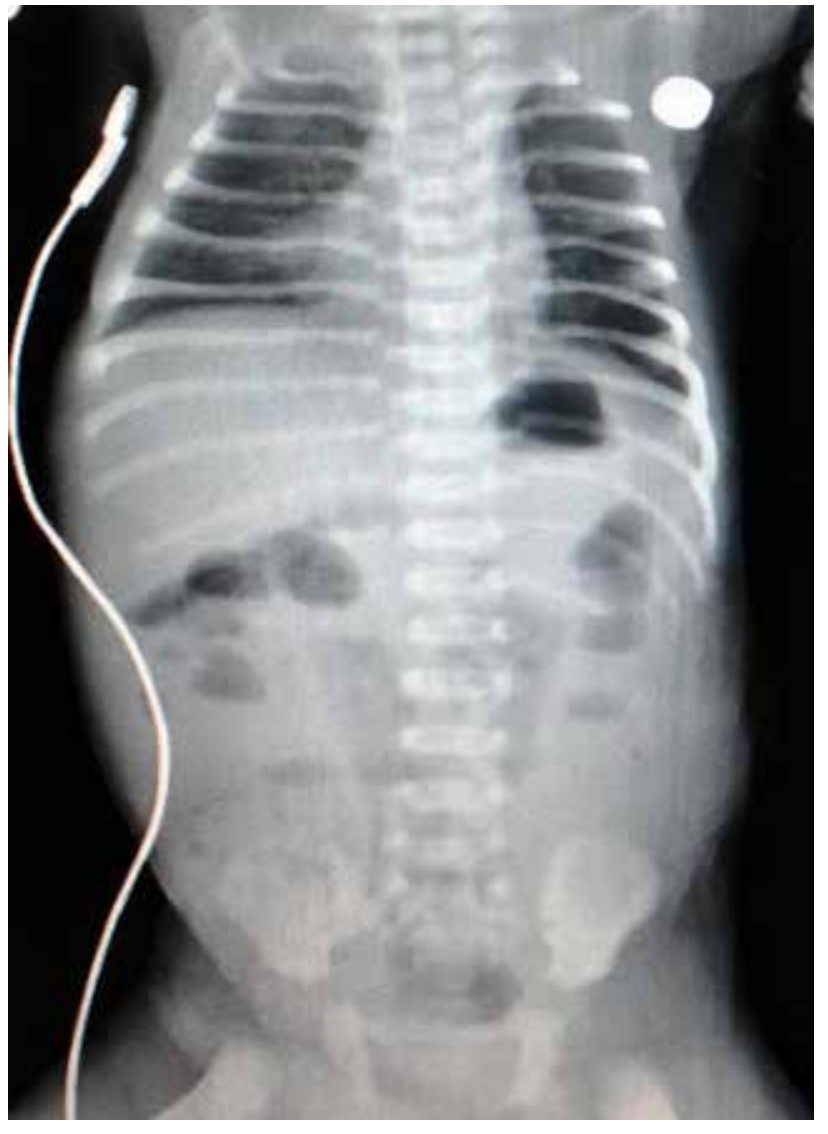

FIGURE 1. Upright, plain abdominal radiograph.

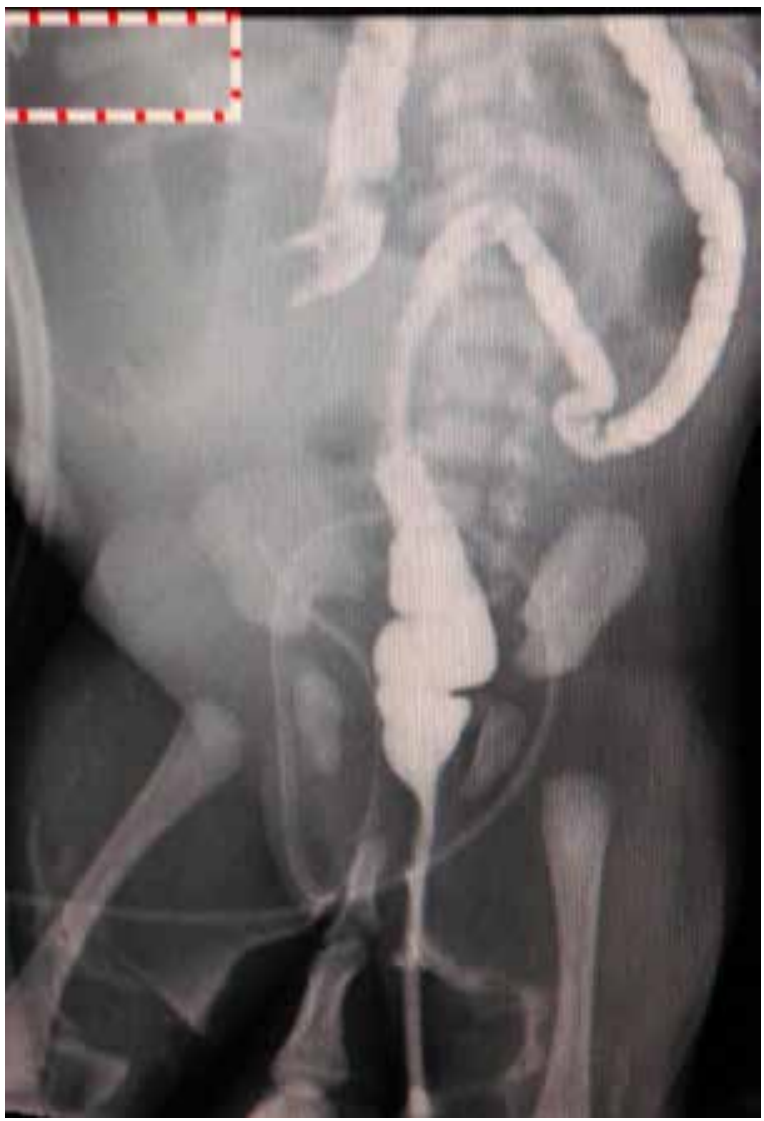

FIGURE2. Barium enema radiograph. genital band compression on ileal loops (Figure 3). Intestinal integrity and passage were intact and not disrupted by excision of band. No remnant of omphalomesenteric canal was found. On postoperative forth day, patient was fed through nasogastric tube. On postoperative sixth day, patient was fed wholly through oral route. Patient was discharged on postoperative 10th day with oral intake and spontane-

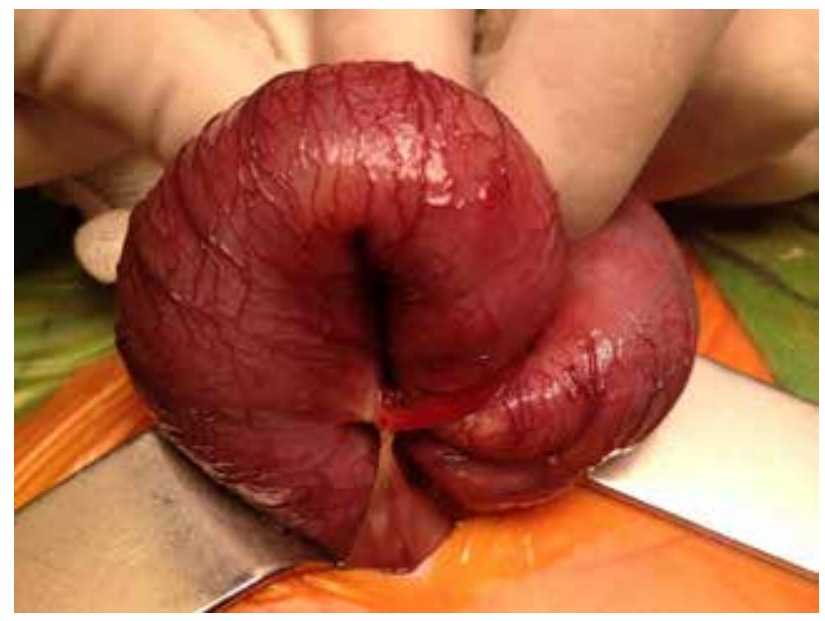

FIGURE 3. Band compression. 
ous defecation. Patient follow-up continued and revealed no medical problem.

\section{DISCUSSION}

During neonatal period, intestinal obstruction requires emergency surgery. Causes of intestinal obstruction include duodenal, jejunal, ileal, and colonic atresia; volvulus; annular pancreas; or congenital bands. Cases other than congenital bands can be diagnosed during prenatal period, and pathologies secondary to congenital bands manifest themselves thereafter. Congenital bands can be in the form of omphalodiverticular, omphalomesenteric or mesodiverticular bands; simple bands with unknown origin have been also reported [2,6]. In the literature, 2 patients with congenital bands diagnosed at 8 days and 3 weeks of age, respectively, have been reported $[7,8]$. Both cases presented at hospital with vomiting and abdominal distension after they had been sent home following birth, and band compression due to Meckel diverticulum was found. In the present case, patient with suspected intestinal obstruction was examined, and surgery was performed with the same diagnosis. Unlike the literature, no remnant of omphalomesenteric canal was found; however, a band extending from mesenteric towards antimesenteric aspect of the ileum was seen.

In the literature, vascular problems and band compression have been reported as possible causes of intestinal atresia [9]. In 1922, Davis and Poynter suggested that intestinal atresia stem from an intrauterine problem [10]. In 1955, Louw and Bernard asserted that occlusion of mesenteric vessels can result in atresia, and Nixon and Tawes reported cases of atresia that occurred following cases of volvulus [10]. Many theories have been proposed, but as yet none can be proven. Since congenital band compression resulted in symptoms during prenatal period in the present case, it may shed light on pathophysiology of intestinal atresia. Development of band compression during last stages of pregnancy may explain why intestinal atresia did not occur in this case.

Some authors prefer minimally invasive approaches for patients with intestinal obstruction during childhood [8,11]. In those instances, pathology was related to Meckel diverticulum, and delayed referral was the issue. In the present case, patient was very young, initial diagnosis was made during prenatal period, and inability to demonstrate continuum of intestinal passage suggested atresia, leading to decision for open surgery.

During neonatal period, though it may be rare, surgery based on indication of intestinal obstruction may reveal simple congenital band compression rather than atresia. It is treated by excising the band, and examining entire intestinal loop for concomitant presence of atresia.

Conflict of Interest: No conflict of interest was declared by the authors.

Financial Disclosure: The authors declared that this study has received no financial support.

Authorship contributions: Concept - E.A.; Design - E.A.; Supervision - E.A.; Funding - E.A.; Materials - E.A.; Data collection and/or processing - E.A.; Analysis and/or interpretation - E.A.; Literature search - E.A.; Writing - E.A.; Critical review - E.A.

\section{REFERENCES}

1. Akgur FM, Tanyel FC, Buyukpamukcu N, Hicsonmez A. Anomalous congenital bands causing intestinal obstruction in children. J Pediatr Surg 1992;27:471-3. Crossref

2. Maeda A, Yokoi S, Kunou T, Tsuboi S, Niinomi N, Horisawa M, et al. Intestinal obstruction in the terminal ileum caused by an anomalous congenital vascular band between the mesoappendix and the mesentery: report of a case. Surg Today 2004;34:793-5.

3. Adedeji OA, McAdam WA. Small bowel obstruction due to encapsulation and abnormal artery. Postgrad Med J 1994;70:1323. Crossref

4. Fujimoto T, Segawa O, Lane GJ, Esaki S, Miyano T. Laparoscopic surgery in newborn infants. Surg Endosc 1999;13:773-7.

5. Goyal MK, Bellah RD. Neonatal small bowel obstruction due to Meckel diverticulitis: Diagnosis by ultrasonography. J Ultrasound Med 1993;12:119-22.

6. Sy ED, Shan YS, Tsai HM, Lin CH. Meckel's diverticulum associated with ileal volvulus in a neonate. Pediatr Surg Int 2002;18:529-31. Crossref

7. Loh AHP, Prasad STR, Chew SH. Neonatal intestinal volvulus due to a persistent right vitelline artery. Pediatr Surg Int 2007;23:373-6. Crossref

8. Kandpal DK, Siddharth S, Balan S, Chowdhary SK. Intestinal obstruction in a premature baby: Endoscopic diagnosis and management by minimal access surgery. J Indian Assoc Pediatr Surg 2013;18:118-20. Crossref 
9. Nayci A, Avlan D, Polat A, Aksoyek S. Ileal atresia associated with a congenital vascular band anomaly: observations on pathogenesis. Pediatr Surg Int 2003;19:742-3. Crossref

10. Frischer JS, Azizkhan RG. Jejunoileal atresia and stenosis. In:
Coran AG, editors. Pediatric surgery. 2012; p. 1059-1071. Crossref 11. Li B, Chen WB, Wang SQ, Liu SL, Li L. Laparoscopy-assisted surgery for neonatal intestinal atresia and stenosis: A report of 35 cases. Pediatr Surg Int 2012;28:1225-8. Crossref 